\title{
O QUE ESTÁ POR TRÁS DA RESPONSABILIDADE SOCIAL CORPORATIVA DO SETOR EXTRATIVO?:
}

\author{
Luiz Jardim Wanderley* \\ * Universidade Federal Fluminense, Departamento de Geografia, Niterói, RJ, Brasil.
}

ACSELRAD, H. (org.). Políticas territoriais, empresas e comunidades: o neoextrativismo e a gestão empresarial do "social". Rio de Janeiro: Garamond, 2018.

Nas Ciências Sociais, em particular nas brasileiras, existe a necessidade de nos aprofundarmos no entendimento do exercício do poder e das estratégias corporativas das empresas extrativas, tanto de maneira macroescalar, no âmbito das redes globais, como nas ações junto aos Estados (nacionais e regionais), até a escala local, das disputas territoriais deflagradas contra as comunidades atingidas no processo de instalação e operação dos empreendimentos. A necessidade de uma agenda de pesquisa acerca das estratégias das corporações extrativas tornou-se flagrante nas últimas duas décadas, quando o boom das commodities minerais (resultante da elevação dos preços no mercado internacional) alterou o comportamento das corporações, dos Estados nacionais e dos movimentos sociais em face da economia extrativa e provocou diversos efeitos na América Latina e em outras regiões da periferia global. Esse período, sob predomínio do capital financeiro, foi denominado neoextrativismo (ACOSTA, 2011; GUDYNAS, 2009).

O livro Políticas territoriais, empresas e comunidades: o neoextrativismo e a gestão empresarial do "social", organizado por Henri Acselrad (2018) e composto de dez artigos de doze autores, cumpre o importante papel de diminuir as limitações teóricas e empíricas existentes no debate sobre as corporações e suas políticas sociais nas regiões periféricas ricas em recursos naturais. Sobretudo, porque se

1.O autor agradece a Fundação de Amparo à Pesquisa do Estado do Rio de Janeiro (FAPERJ) pelo apoio financeiro por meio do Edital Grupos Emergentes. 
trata de um fenômeno recente no contexto do capitalismo neoliberal globalizado, intensificado a partir dos anos 2000, com destaque para as estratégias corporativas denominadas Responsabilidade Social Corporativa (RSC) e seus efeitos sociais sobre o exercício dos direitos básicos. Além disso, o fenômeno social investigado pelos autores carrega características de transformação constante, por ser resultante da interação de diferentes agentes sociais, econômicos e políticos, que obrigam a readaptação permanente das estratégias das corporações em resposta, às também mutáveis, críticas sociais direcionadas a elas (GIFFONI PINTO, 2013), e por conta das diferentes geografias dos espaços em disputa. Toda essa complexidade social e contemporaneidade dos novos processos de produção capitalista do espaço justifica a necessidade de inserir as estratégias das corporações do setor extrativo na agenda de pesquisa das ciências sociais brasileiras (SANTOS; MILANEZ, 2017).

Essa obra é resultado do desdobramento teórico de pesquisas e reflexões de Acselrad, em diálogo com diferentes colaboradores nas últimas décadas. Não podemos ignorar os esforços anteriores de incorporação da questão ambiental no debate sobre justiça e democracia e, especialmente, a análise sobre os impactos e injustiças ambientais dos grandes projetos na Amazônia (ACSELRAD, 1991). Todavia, foi a introdução das noções de conflito ambiental (ACSELRAD, 2004) e justiça ambiental (ACSELRAD; PÁDUA; HERCULANO, 2004) que orientou novas abordagens teóricas sobre os impactos ambientais e as disputas por recursos naturais deflagradas pela apropriação material e simbólica das corporações extrativas sobre a natureza, assim como as leituras sobre os movimentos de resistência, que ganhavam visibilidade no país no início do século XXI. Estudos sobre os conflitos e as estratégias de controle do território, da terra e da natureza, tanto das corporações como do Estado e dos movimentos sociais, foram aprofundados em diferentes publicações coletivas (ACSELRAD, 2010; 2013). A centralidade dessas obras estava em entender a disputa territorial a partir da "guerra dos mapas” e das técnicas cartográficas, em especial as ferramentas de luta da cartografia social, que possibilitam reafirmar identidades, reivindicar direitos territoriais e fortalecer os processos políticos de resistência às corporações extrativas.

O livro em foco tem como objetivo analisar as empresas extrativas e suas ações sociais, desvelando seus efeitos e intencionalidades com abordagens teóricas e análises empíricas. Com isso, os estudos de diferentes países latinos - Argentina, Brasil, Guatemala, México e Peru -, da Oceania - Papua-Nova Guiné - e da África República Democrática do Congo - demostraram, em amplo espectro de situações, como diferentes mineradoras se utilizam de estratégias, em múltiplas escalas, para assegurar o controle sobre recursos e pessoas por meio do espaço e de políticas sociais. Isto é, são ações sociais empresariais extramuros que visam legitimar os 
projetos extrativos e assegurar os fluxos produtivos nos territórios, como prevenção ao "risco social" sobre os negócios decorrente de conflitos e reações indesejáveis.

O texto da palestra de Alain Deneault centra-se na questão do poder soberano das empresas multinacionais, em específico do setor do petróleo, diante dos Estados e da população. Deneault aponta que, no início do século XX, os Estados hegemônicos permitiram a formação do cartel de grandes petroleiras para garantir a estabilidade de fornecimento, jurídica e econômica, ao mercado de petróleo. Associadas aos cartéis, foram construídas legislações ultrapermissivas de gestão de capitais em paraísos fiscais, que possibilitam realizar práticas financeiras proibidas na maioria dos países. Os Estados, neste contexto, assumem a lógica de operação privada, capturada por lobbies de interesse empresariais e por mecanismos de porta giratória, encontrando-se coagidos pela chantagem da dívida pública. As empresas, por sua vez, afirmam operar de acordo com as normas estatais, deslocando as críticas sociais para a (in)ação do Estado, o que o autor definiu como poder perverso (p. 23). Ele sustenta, por fim, que o fato de as multinacionais terem poder rizomático, organizado em redes globais, é o que lhes permite driblar as legislações mais restritivas, livrando-as de taxações, multas ou responsabilidade judicial.

Henri Acselrad, em seu artigo, comenta a intensificação recente da intervenção das corporações sobre a instância política, utilizando-se de microtecnologias de poder, como estratégia de "não mercado", para diminuir os riscos provocados por movimentos sociais contestatórios e como forma de legitimar a construção de territórios de capitalismo extrativo de base neoliberal. A gestão da incerteza política exige, então, a construção de um mapa "político do tempo e do espaço de lutas sociais” (p. 34), mas também a necessidade de informações detalhadas sobre os grupos capazes de afetar os negócios, seus modos de vida e necessidades sociais, com o propósito de formular políticas territoriais que visam à obtenção de consentimento e à estabilidade social. No setor extrativo, as ações sociais diretas, na perspectiva das empresas, são ainda mais necessárias, tendo em vista que a imobilidade dos recursos naturais e os graves impactos causados transformam os conflitos com as comunidades locais nas maiores ameaças aos investimentos. Por fim, o autor afirma que os espaços formais de participação, mediados pelo Estado, assim como as políticas públicas de direitos, estão sendo substituídas pela ação de "quase Estados", que promovem uma regulação empresarial dos conflitos, implementando regimes de exceção de permanente vigilância e controle dos grupos críticos e, por outro lado, incentivando programas sociais assistencialistas.

Com análise original sobre o que chamou de Cluster Minerador Global (p. 61), Claudio Garibay Orozco explica como as corporações mineradoras transnacionais se organizaram, desde a Rio-92, numa poderosa coalizão (bloco ideológico) capaz 
de impor a agenda mineral a quem define a política e a economia. $\mathrm{O}$ autor demonstrou a centralidade de instituições internacionais do setor, como o ICMM ${ }^{2}$, na formulação de políticas (protocolos e ferramentas técnicas) que orientam a forma de coerção social sobre diferentes escalas de poder estatal e comunitário. Elas também são responsáveis pela construção de discursos teoricamente fundamentados na defesa de princípios da "mineração sustentável" e socialmente bondosa, que buscam rebater as críticas sociais e legitimar o controle socioterritorial e a destruição ambiental. Esse "sujeito político global” resulta do contexto de transformações recentes do setor, que se financeirizou globalmente e incorporou a tecnologia de mineração em grande escala, expandindo a fronteira mineral no mundo. Com base no caso mexicano, o autor detalhou o processo de incorporação da filosofia do cluster na esfera neoliberal estatal e o horizonte de coerção (p. 86) sobre as redes sociais locais, além da resistência à política de desapropriações da mineradora canadense Goldcorp no Valle de Mazapil.

A pesquisa de Jana Hönke comprovou a existência da continuidade da governança empresarial de intervenção nas comunidades, ao comparar o início do século XX e o começo do XXI, na República Democrática do Congo. Mostrou-se, contudo, que, nos "cinturões comunitários" das áreas de operação mineral, ocorreu um deslocamento de políticas paternalistas coercitivas e disciplinadoras - que almejavam o isolamento social da força de trabalho e a introdução dos costumes europeus - para gestões participativas - operadas por "poderosas técnicas de coerção e governo indireto” (p. 108), por meio de mecanismo de mercado, participação e responsabilização individual. As comunidades locais são, ao mesmo tempo, agentes que disputam terra e minério com as corporações e parceiras no policiamento do entorno do empreendimento. No âmbito da gestão participativa, comitês e fóruns de desenvolvimento local, constituídos por setores não críticos, se tornam estruturas paralelas ao Estado para negociar diretamente com as empresas. Somado a isso, os chefes tribais locais recebem pagamentos diretos em troca de paz social e de comprometimento da população ${ }^{3}$. Essas são algumas características do caso africano, que inclusive se aparentam com as ações corporativas na América Latina.

O trabalho de Raquel Giffoni Pinto mostrou como o "risco social”, isto é, a ameaça da pressão da sociedade civil sobre os investimentos extrativos, se transformou num dos principais desafios das empresas. A autora aprofunda a compreensão das políticas de responsabilidade social por dentro das pouco investigadas empre-

2. Conselho Internacional de Mineração e Metais.

3. As empresas pesquisadas foram a Freeport MacMoRan (Estados Unidos), First Quantum (Canadá) e Anvil Mining (Austrália). 
sas de consultoria - idealizadoras e operadoras das “tecnologias” de neutralização da crítica social e de estabilização do terreno político. E conclui que, em alguns contextos, os profissionais das Ciências Sociais colaboram para o funcionamento da "máquina antipolítica" (p. 153), ao avaliar os impactos causados pelos grandes projetos e gerenciar os conflitos deles decorrentes.

Nas últimas décadas, a profusão de projetos mineradores em zonas não tradicionalmente mineradas, como é o caso da Argentina, reflete o contexto de novas tecnologias de extração de minérios de baixo teor, a elevação dos preços dos minérios e a flexibilização neoliberal das políticas. Analisando as regiões periféricas do território argentino, Julieta Godfrid investigou a estratégia de construção de consenso e de melhoria da imagem das mineradoras perante os conflitos ambientais gerados, que contribuíram para a imagem negativa do setor no país. Os casos dos megaprojetos de Valadero ${ }^{4}$ e Alumbrera ${ }^{5}$ expressam as diferentes fases da percepção nacional sobre mineração e os conflitos causados por impactos e desastres ambientais, que resultaram em distintas reações populares e respostas empresariais. Para a autora, as práticas de RSC variam de acordo com a agitação social. Elas seriam de dois tipos: intervenção socioterritorial ou discursiva (p. 168), com diferentes modalidades de iniciativas anteriormente pertencentes à esfera pública.

Catherine Coumans analisa como as corporações mineradoras respondem às críticas de violação de direitos humanos, utilizando como exemplos casos na Guatemala e em Papua-Nova Guine. O texto destaca a ausência de uma regulação global capaz de garantir melhorias no comportamento das empresas transnacionais em relação aos direitos humanos, por não haver obrigatoriedade vinculante aos cumprimentos das normas da ONU - limitadas a princípios orientadores de cumprimento voluntário. No Canadá, tentou-se criar um arcabouço jurídico legal de responsabilização das empresas e dos investidores canadenses em caso de violação de direitos humanos em outros países. A proposta não foi adiante devido à resistência empresarial. Nos estudos de caso, a pesquisadora explicitou que as mineradoras Goldcorp e Barrick Gold Corporation utilizaram ferramentas de direitos humanos (especificamente, a Avaliação de Impactos em Direitos Humanos e o Mecanismo de Denúncia de nível operacional para garantir reparação), de modo a atender os interesses corporativos, provocando danos e violações aos atingidos por conta do controle das ferramentas pelas empresas, da falta de transparência, da ausência de legitimidade e das reparações injustas.

\footnotetext{
4. Projeto da empresa Yacimientos Mineros Aguas de Dionisio com a Minera Alumbrera (a anglo-suíça Glencore e as canadenses Goldcorp e Yamana Gold).

5. Subsidiária da Barrick Gold Corporations (Canadá).
} 
Dois artigos discutem as estratégias de duas mineradoras na Amazônia brasileira. No primeiro, Edwin Muñoz Gaviria aponta como as políticas de governança são implementadas pelas corporações, com a participação do Estado e de parte da sociedade local, com vistas a gerir recursos econômicos de forma a tornar consensual o desenvolvimento de base mineral e estabelecer confiança coletiva nos benefícios da mineração. O caso Juruti Sustentável, com a construção do fórum e do conselho de base local, de indicadores de monitoramento e do fundo de desenvolvimento, exemplifica a morfologia da política privada de governança da Alcoa. Essas políticas produzem espaços de decisão assimétricos, excludentes de grupos críticos, que esvaziam a esfera pública e fortalecem o poder e a legitimidade corporativa e de seus projetos sociais.

Igor Pantoja, por sua vez, descreveu o planejamento social privado da Vale S/A, concebido com base em estudos prévios pela Fundação Vale, o braço social da empresa, e executado por ONGs e empresas de consultoria contratadas. O pesquisador constatou a elevação recente dos investimentos sociais da mineradora, demonstrando o ganho de importância interna da estratégia de promoção de políticas sociais em resposta à emergência de grupos críticos. Além disso, destacou o protagonismo e a influência da Fundação junto ao poder público em diferentes esferas, por meio dos quais conquista políticas e recursos públicos para os municípios e até mesmo para o financiamento de seus projetos sociais.

O último artigo, produzido por Gerardo Damonte Valencia, Camilo León Castro e Boris Dávila Cáceres, apoia-se na experiência peruana e propõe sistematizar as ações corporativas das mineradoras segundo vários critérios: fases dos empreendimentos (exploratória; exploração e encerramento); políticas de desenvolvimento (industrial; apoio social, desenvolvimento sustentável); e estratégias de relação com a comunidade (isolamento, transação, relações públicas, subvenção e participativa). Os autores destacam que as diferentes ações das mineradoras variam de acordo com a magnitude do empreendimento, o tamanho da empresa, seu grau de internacionalização e os tipos de comunidades afetadas. Eles ressaltam, ainda, os efeitos e as limitações sobre o desenvolvimento econômico local: geração de emprego; aquisições de produtos e serviços, melhoria de serviços públicos básicos e desenvolvimento comunitário. A sistematização exposta dialoga diretamente com as estratégias empresariais analisadas nos demais estudos do livro.

À luz das reflexões críticas presentes em Políticas territoriais, empresas e comunidades, podemos evocar o discurso de Milton Friedman (1970), no qual afirma que o único compromisso das empresas é com o lucro privado. Esse economista liberal classificou a proposta da responsabilidade social das empresas como resultado da aceitação de uma visão socialista, que transfere recursos da reprodução 
do capital para uso social. Por outro lado, ele reconhece que as ações sociais das firmas e de seus gestores servem como disfarce para interesses direcionados exclusivamente para assegurar a lucratividade.

A coletânea em discussão, em seus diferentes capítulos, desconstrói o discurso da responsabilidade social corporativa, analisando o papel político das ações sociais diretas das empresas nos espaços onde operam ou desejam se instalar. Além disso, revela como as práticas de responsabilidade social se tornaram estratégias globais fundamentais para a dominação do espaço, de recursos e de pessoas, com a finalidade de forjar consenso, neutralizar a crítica social e diminuir os riscos sociais aos investimentos. No setor extrativo, isso mostra-se ainda mais necessário, por conta da menor mobilidade locacional das empresas, em virtude da rigidez espacial dos recursos minerais; mas também pelo elevado grau de conflitos e impactos de ordem social e ambiental gerados às populações. Neste contexto, novos espaços de gestão política e de recursos para compensação são criados com o protagonismo das empresas, enfraquecendo os atores coletivos críticos e os espaços públicos democráticos de decisão. Desmontam-se assim os alicerces políticos e sociais que permitiriam fazer florescer o debate sobre alternativas ao desenvolvimento local e regional. Muitas dessas constatações são novas e contribuem para a reflexão crítica do capitalismo extrativo na periferia global.

\section{Referências}

ACOSTA, A. Extractivismo y neoextractivismo: dos caras de la misma maldición. In: GRUPO PERMANENTE DE TRABAJO SOBRE ALTERNATIVAS AL DESARROLLO. Más alla del desarrollo. Quito: AbyaYala, Fundación Rosa Luxemburg, 2011.

ACSELRAD, H. (org.). Políticas territoriais, empresas e comunidades: o neoextrativismo e a gestão empresarial do “social”. Rio de Janeiro: Garamond, 2018.

. (org.). Cartografia social, terra e território. Rio de Janeiro: Ippur/UFRJ, 2013. (Coleção Território, Ambiente e Conflitos Sociais n. 3).

(org.). Cartografia social e dinâmicas territoriais: marcos para o debate? Rio de Janeiro: Ettern/Ippur, 2010.

. (org.). Conflitos ambientais no Brasil. Rio de Janeiro: Relume Dumará, 2004.

Planejamento autoritário e desordem socioambiental na Amazônia: crônica do deslocamento de populações em Tucuruí. Revista de Administração Pública, Rio de Janeiro, n. 25, p. 53-68, 1991.

ACSELRAD, H.; PÁDUA, J. A; HERCULANO, S. (org.). Justiça ambiental e cidadania. Rio de Janeiro: Relume Dumará, 2004.

FRIEDMAN, M. The Social Responsibility of Business is to Increase its Profits. The New York Times Magazine, September 13, 1970. 
GUDYNAS, E. Diez tesis urgentes sobre el nuevo extractivismo. In: CENTRO ANDINO DE ACCION POPULAR (CAAP); CENTRO LATINO AMERICANO DE ECONOLOGÍA SOCIAL (CLAES) (Ed.). Extractivismo, política y sociedad. Quito: Caap; Claes, 2009. p. 187-225.

GIFFONI PINTO, R. O poder da crítica: um estudo sobre a relação empresa e movimentos sociais em um contexto de conflito ambiental. Estudos de Sociologia, Araraquara v. 18, p. 307-324, 2013.

SANTOS, R; MILANEZ, B. Estratégias corporativas no setor extrativo: uma agenda de pesquisa para as ciências sociais. Caderno Eletrônico de Ciências Sociais, v. 5, p. 1-26, 2017. 


\section{Luiz Jardim Wanderley}

Geógrafo, doutor em Geografia pela Universidade Federal do Rio de Janeiro (UFRJ). Professor do Departamento de Geografia da Universidade Federal Fluminense (UFF) e do Programa de Pós-Graduação em Geografia da Universidade do Estado do Rio de Janeiro (Uerj-FFP). Membro do Grupo de Pesquisa e Extensão - PoEMAS - Política, Economia, Mineração, Ambiente e Sociedade.

Email: luizjardim@id.uff.br

ORCID: 0000-0002-6321-0254

Submissão: 14 de abril de 2020.

Aprovação: 24 de junho de 2020.

Como citar: WANDERLEY, L. J. O que está por trás da Responsabilidade Social Corporativa do setor extrativo?. Revista brasileira de estudos urbanos e regionais. v.22, E202020, 2020. DOI 10.22296/2317-1529.rbeur.202020

Artigo licenciado sob Licença Creative Commons CC BY-NC 4.0. https://creativecommons.org/licenses/by-nc/4.o/deed.pt_BR 